\title{
Interaction between phloretin and insulin: a spectroscopic study
}

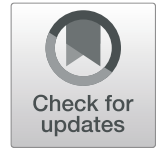

Sahri Yanti, Zhong-Wen Wu, Dinesh Chandra Agrawal and Wei-Jyun Chien ${ }^{*}$

\begin{abstract}
Diabetes is among the top ten deadly diseases in the world. It occurs either when the pancreas does not produce enough insulin (INS) or when the body cannot effectively use the insulin it produces. Phloretin (PHL) has a biological effect that can treat diabetes. A spectroscopic study was carried out to explore the interaction between phloretin and insulin. UVNis spectroscopy, fluorescence spectroscopy, and circular dichroism spectropolarimeter were used in the study. UVNis spectra showed that the interaction between PHL and INS produced strong absorption at a wavelength of $282 \mathrm{~nm}$. The fluorescence analysis results showed that the excitation and emission occurred at 280-nm and 305-nm wavelengths, respectively. Temperature changes did not affect INS emissions. However, the interaction of PHL-INS caused a redshift at 305 to $317 \mathrm{~nm}$. Temperature affected the binding constant $\left(K_{a}\right)$ and the binding site $(n)$. Ka decreased with increasing temperature and increased the binding site. The thermodynamic parameters such as enthalpy $\left(\Delta H^{0}\right)$ and entropy $\left(\Delta S^{0}\right)$ each had a value of $-16,514 \mathrm{~kJ} / \mathrm{mol}$ and $22.65 \mathrm{~J} / \mathrm{mol} \cdot \mathrm{K}$. PHL and INS interaction formed hydrogen bonds and hydrophobic interaction. The free energy $\left(\Delta \mathrm{G}^{0}\right)$ recorded was negative. PHL and INS interactions took place spontaneously. The quenching effect was dynamic and static. $K_{D}$ values were greater than $K_{S}$. The higher the temperature, the less was $K_{D}$ and $K_{S}$. The appearance of two negative signals on circular dichroism (CD) spectropolarimeter implies that phloretin could induce regional configuration changes in insulin. The addition of PHL has revealed that the proportion of a-helix in the insulin stabilizes its structure. Phloretin's stabilization and enhancement of the a-helix structural configuration in insulin indicate that phloretin can improve insulin resistance.
\end{abstract}

Keywords: Insulin resistance, Phloretin, Fluorescence quenching, Circular dichroism

\section{Introduction}

Diabetes is among the top ten deadly diseases in the world. It occurs when the pancreas does not produce enough insulin or when the body cannot effectively use the insulin it produces. According to an estimate, nearly 500 million people live with diabetes worldwide, and the number is projected to increase every year. Insulin that enters the blood can reach glucose transport, increase glycogen synthesis, and inhibit sugar regeneration in the liver and skeletal muscles (Brown and Walker 2016). The biological effect of the hormone begins with the binding of insulin to its target cell membrane receptors.

\footnotetext{
* Correspondence: wjchien@gm.cyut.edu.tw

Department of Applied Chemistry, Chaoyang University of Technology, 168, Jifeng E. Rd., Wufeng District, Taichung City 413310, Taiwan
}

Once bound to tyrosine kinase receptor (RTK), the configuration insulin changes, causing autophosphorylation. Also, it can catalyze the phosphorylation of specific tyrosine residues while interacting with other proteins (Rodelo et al. 2017). Insulin is composed of unstable monomers and tends to form aggregations in solution (Chiti and Dobson 2006; Dunn 2005; Grasso et al. 2016). Also, insulin forms dimer crystals when it loses divalent metal ions. These crystals can be divided into cubic crystals at neutral $\mathrm{pH}$ and orthorhombic at acidic $\mathrm{pH}$ (Whittingham et al. 2002; Yao et al. 1998).

Spectroscopic methods have been used to study the interaction of human serum albumin with various types of ligands (Al-Mehizia et al. 2019; Alanazi et al. 2019; Alsaif et al. 2020b; Kandagal et al. 2006; Meti et al. 2015; Wani et al. 2021a; Zargar et al. 2020). The interaction of
Springer Open (c) The Author(s). 2021 Open Access This article is licensed under a Creative Commons Attribution 4.0 International License, which permits use, sharing, adaptation, distribution and reproduction in any medium or format, as long as you give appropriate credit to the original author(s) and the source, provide a link to the Creative Commons licence, and indicate if changes were made. The images or other third party material in this article are included in the article's Creative Commons licence, unless indicated otherwise in a credit line to the material. If material is not included in the article's Creative Commons licence and your intended use is not permitted by statutory regulation or exceeds the permitted use, you will need to obtain permission directly from the copyright holder. To view a copy of this licence, visit http://creativecommons.org/licenses/by/4.0/. 
protein molecules in Thymus DNA with abiraterone was also studied using spectroscopic methods (Alsaif et al. 2020a; Wani et al. 2020a). Insulin has interacted with vitamin E (Soleymani et al. 2016). There are three types of chromophore groups in proteins, which have different electron absorption band characteristics. The first chromophore is a peptide bond that connects one amino acid to another. The absorption is weak and can be detected at a wavelength of $220 \mathrm{~nm}$. The second type of chromophore constitutes aromatic amino acids such as phenylalanine, tyrosine, tryptophan, and histidine. The chromophore peaks are located at $230 \mathrm{~nm}$ and $300 \mathrm{~nm}$ wavelengths. The third chromophore comes from the presence of metal ions and $\pi$ (phi) electrons. The strong absorption in the visible region is due to the influence of the prosthetic group. Proteins usually have absorption at wavelengths of $275 \mathrm{~nm}$ and $280 \mathrm{~nm}$. It is due to tryptophan, tyrosine, and aromatic amino acids at these wavelengths and possibly due to cysteine, which is composed of disulfide bonds. Changes in structure occur due to changes in the environment of amino acids. Observations were made on the conditions before and after complex bond formation (Nienhaus and Nienhaus 2005; Zhang et al. 2008). The wavelength and intensity of absorption depend on the chemical properties and physical condition of the molecule.

Analysis using absorption spectroscopy has been carried out by dissolving organic and inorganic molecules in a transparent solvent medium. Ultraviolet/visible light spectroscopy has been used to study the ligand binding of proteins and their effects on their structures. Ultraviolet/visible light spectroscopy is a powerful tool in measuring protein-ligand interactions (Le Han et al. 2009). The absorbance was proportional to the solution's concentration and was used as a quantitative measurement (Alsanea et al. 2017).

Competitive reactions can occur between proteins with proteins and proteins with ligands. The interaction of the protein with protein causes polymerization and is characterized by increasing $n$ (binding site) and $K$ (binding constant) values. Polymerization occurs when the albumin concentration is increased (Fernandez et al. 1993). High flavonoid concentration as a ligand causes competition between them and even moves from the protein site (Wani et al. 2021b). Interaction occurs between proteins as donors and ligands as acceptors. Donors can produce fluorescent light. The fluorescence emission spectra overlap with the absorbance spectra of acceptor molecules so that the binding sites of Try with small molecules can be predicted through fluorescence observations. The Try can be the center of the binding regions or close to the binding regions if it experiences a quenching effect. This quenching effect can be a reference for studying the configuration of protein molecules in the solution. Changes in the microenvironment around fluorescent clusters may be relevant evidence for binding proteins to small molecules (Ding et al. 2009). Fluorescence microscopy can provide information about the excitation spectrum, emission, fluorescence intensity, quantum yield, fluorescence lifetime, etc.. This value can reflect the behavior of the molecule at various angles. Many researchers have observed molecular configurations and analyzed these parameters (Iannuzzi et al. 2017a; Lakowicz and Weber 1973; Seedher and Bhatia 2006; Wang et al. 2001). Circular dichroism (CD) spectropolarimeter is a rapid spectroscopic technique in determining protein molecules' secondary structure and fold characteristics. This technique is widely used to study protein stability and whether configuration changes can form folds or mutations. Several researchers have used a CD spectropolarimeter (Gilg et al. 1996; Kachooei et al. 2014; Matsuo et al. 2005). The secondary structure of different proteins produces a CD spectropolarimeter spectrum with different characteristics. The combination of fluorescent and $\mathrm{CD}$ data shows that there is induction of polypeptide bonds, changes in protein conformation, and exposure in hydrophobic regions (Le Han et al. 2009).

Substitution of water molecules by ligands inside and outside the enzyme molecule can cause stability problems and reduce the strength of important covalent bonds so that the enzyme becomes inactive. Enzyme function will be lost if its orientation and proximity to the substrate molecule are lost. This can be detected through the reduced amino acid binding site (HashemiShahraki et al. 2020). Molecular docking can predict ligand-binding sites on proteins to the atomic level. Non-covalent interactions between proteins and drugs are divided into four types: hydrogen bond interactions, van der Walls interactions, hydrophobic interactions, and electrostatic interactions (Shi et al. 2013). The distance of $2.264 \mathrm{~nm}$ causes Van der Waals interactions and hydrogen bond interactions on Trp (donor) and prednisolone (acceptor) (Shi et al. 2013). Van der Waals interactions and hydrogen bonding also occur in pepsin, and naphthol yellow decease the affinity of pepsin to the substrate (Hashemi-Shahraki et al. 2020).

Flavonoids are natural compounds used for the treatment of chronic diseases such as obesity and diabetes. Phloretin is a type of flavonoid found in the skins of apples and pears. Phloretin has biological activities such as antioxidant, antitumor, anti-inflammatory, liver damage repair, and insulin resistance (Shen et al. 2017). The present study aims (i) to explore the interaction between insulin and phloretin by spectroscopy, (ii) to observe the change of insulin absorbance by UV/visible spectrometer after adding phloretin, (iii) to study the interaction between insulin and small molecules affecting the 
fluorescence quenching, and (iv) to observe the changes in the secondary structure of insulin by the circular dichroism spectroscopy and explore whether the addition of phloretin can stabilize the secondary structure of insulin. The study's outcome has potential application in medical research and the treatment of diabetic patients.

\section{Materials and methods}

The materials used in this study included insulin (99\%) CAS 30003-72-6, L-tyrosine (98\%) CAS 60-18-4, and phloretin (99\%) CAS 60-82-2 (purchased from Sigma Aldrich), hydrochloric acid ( $\mathrm{pH}=2.0)$ CAS 7722-84-1, methanol 99.5\% (Merck), and distilled water. The instruments utilized were ultrasonic vibration machine, UV/visible spectrometer (PerkinElmer Lambda 265), fluorescence spectrometer (Jasco FP-750 with Xenon as a fluorescent light source), constant temperature water tank (FIRSTEK Model-B403H), fluorescent holder (Jasco STR-312), circular dichroism (CD) spectropolarimeter (Jasco J-815 with a $150-\mathrm{W}$ Xenon lamp as a light source), and a 1-mL quartz cuvette for sample measurement.

\section{Spectroscopy UV/Vis analysis}

Samples of PHL and INS were diluted using $\mathrm{HCl}(\mathrm{pH}=$ 2.0) and methanol as a solvent. Stock solutions of INS, PHL, and Tyr were made with the following concentrations: $2.9 \mathrm{mg}$ INS with $5 \mathrm{~mL} \mathrm{HCl}, 1.37 \mathrm{mg}$ PHL with 5 $\mathrm{mL} \mathrm{MeOH}$, and $0.18 \mathrm{mg}$ Tyr $10 \mathrm{~mL} \mathrm{HCl}$. The PHL concentration was maintained constantly at $5.0 \times 10^{-5} \mathrm{M}$, while the INS concentration was gradually increased from $2.5 \times 10^{-6}$ to $5.0 \times 10^{-5} \mathrm{M}$. The INS and PHL mixed solutions were made by mixing solutions in various mole ratios of 1:0.05, 1:0.1, 1:0.5, and 1:1 (PHL: INS). The mixture was put into an ultrasonic vibrator for $30 \mathrm{~min}$ and transferred to a 1-mL quartz cuvette to record UV/Vis spectrometer measurements. Homogenization was carried out so that the solutions get mixed. In this study, ultrasonic vibrations were used because their energy is lower than the peptide bonds' breaking energy, composed of strong covalent bonds (Gong et al. 2019). The binding free energy of insulin was $-8.97 \pm 1.41 \mathrm{kcal} / \mathrm{mol}$ or $9.60692 \times 10^{16} \mathrm{kHz}$. The frequency of ultrasonic vibrations was $18-40 \mathrm{kHz}$.

\section{Fluorescence spectroscopy analysis}

The INS and PHL mixed solutions were prepared with different molar ratios of INS: PHL $(1: 0 ; 1: 0.25 ; 1: 0.5 ; 1$ : $0.75 ; 1: 1 ; 1: 1.25 ; 1: 1.5 ; 1: 1.75 ; 1: 2 ; 1: 2.25)$ and put in the ultrasonic vibrator for $30 \mathrm{~min}$ to make it homogeneous. The INS concentration was fixed at $5.0 \times 10^{-5} M$ and PHL concentration was increased from $1.25 \times 10^{-5}$ to $1.25 \times 10^{-4} M$. The samples were analyzed using a fluorescence spectrometer that was set at emission condition mode, excitation, and emission bandwidth at $5 \mathrm{~nm}$, medium sensitivity mode, data pitch of $1 \mathrm{~nm}$, scanning speed at $250 \mathrm{~nm} / \mathrm{min}$, excitation wavelength increased to $280 \mathrm{~nm}$, and scanning range from 190 to $500 \mathrm{~nm}$.

\section{Circular dichroism spectropolarimeter analysis}

In the circular dichroism (CD) spectropolarimeter experiment, the INS-PHL mixed solutions were prepared at the molar ratios of 1:0, 1:2, 1:4, 1:6, 1:8, 1:10, and 1:12 (INS: PHL). The mixed solutions were homogenized using an ultrasonic vibrator for $30 \mathrm{~min}$ before the $\mathrm{CD}$ spectrometer analysis. The INS concentration was prepared at $5.0 \times 10^{-1} \mathrm{M}$, and the PHL concentration was made at the range of $1.0 \times 10^{-5}$ to $6.0 \times 10^{-5} \mathrm{M}$. The mixed solutions in the respected ratio were inserted into a 1-mm quartz cuvette case and measured in a CD spectropolarimeter. The CD spectropolarimeter was set in a bandwidth of $1 \mathrm{~nm}$, standard sensitivity mode, data pitch of $0.5 \mathrm{~nm}$, scanning speed at $50 \mathrm{~nm} / \mathrm{min}$, continuous scan mode, immediate start mode, and scanning range 190 to $260 \mathrm{~nm}$.

\section{Results and discussion \\ Spectroscopy UV/Vis studies of the interaction between INS and PHL}

Electrons in the INS residue serve absorption, excitation, emission, and fluorescence. Fluoresce molecules have absorption at 200-700 nm (Day and Underwood 1991). The electrons transition occurring from $\pi, \pi *$ (Suhartati 2017). The transition $\pi, \pi *$ of the carbonyl group absorption in the protein was found at $210 \mathrm{~nm}$ (HashemiShahraki et al. 2020). Proteins have a chromophore in the form of peptide bonds that appears at $220 \mathrm{~nm}$ (Nienhaus and Nienhaus 2005). INS has an optimum absorption at $275 \mathrm{~nm}$ (Fig. 1a,b). In a previous study, wavelengths of $250-300 \mathrm{~nm}$ have been used to determine insulin absorption in different solvents, and insulin could be detected at a wavelength of $275 \mathrm{~nm}$ (Liefeng et al. 2008). Wavelengths 220-340 $\mathrm{nm}$ have been used, measuring the absorption of insulin interactions with its aptamer (Verdian-Doghaei and Housaindokht 2015). While wavelength at $260-400 \mathrm{~nm}$ is used by Correia et al. (2012). INS has two peaks at $275 \mathrm{~nm}$ and $282 \mathrm{~nm}$ (Fig. 1a,b). The presence of the two peaks in INS is probably due to the absorption of an amine group having a lone electron pair $(275 \mathrm{~nm})$ and an aromatic ring group $(282 \mathrm{~nm})$. Lone pair electrons own by $\mathrm{NH}$ bonds was a componen of protamine. Protamine is composed of arginine, which is rich in $\mathrm{NH}$ bonds. Protamine is a protein that can protect insulin from being degraded by enzymes. The uptake of proteins such as protamine was detected at a wavelength of $275 \mathrm{~nm}$ (Nienhaus and Nienhaus 2005). The aromatic ring is owned by tyrosine, tryptophan, and phenylalanine also have a signals. It was seen at a wavelength of $280 \mathrm{~nm}$ (Hashemi-Shahraki et al. 2020; Kierdaszuk et al. 1995). Amino acid aromatic 

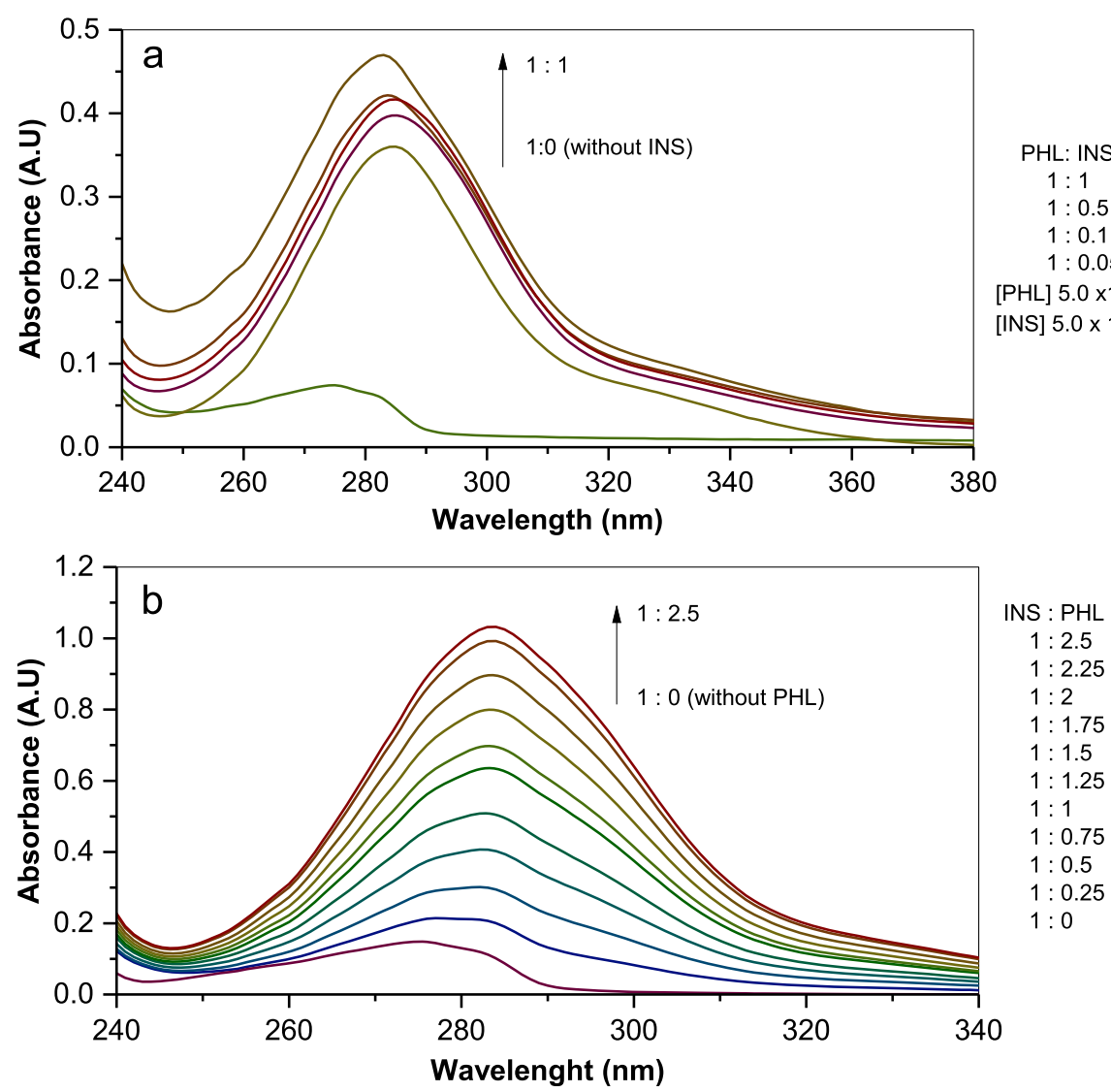

Fig. 1 Absorption Spectrum of PHL after variation of INS (a), INS after variation of PHL (b)

chromophore has an absorption range of $230-300 \mathrm{~nm}$ (Nienhaus and Nienhaus 2005).

When binding occurs, the electrons in the INS residue release energy (fluorescence). At the same time, the electrons in the ligand absorb energy, and the spectra overlap. PHL is a flavonoid compound composed of benzene rings. Prosthetic groups with phi electrons such as chlorophyll, carotenoid, flavin, heme, and retinal are sensitive to the polypeptide environment and can even change the protein structure. The benzene group absorption of PHL overlaps with the aromatic ring absorption of INS. The INS-PHL mixture has an overlapping peak at a wavelength of $283 \mathrm{~nm}$, indicating that INS has shifted the PHL peak from 285 to $283 \mathrm{~nm}$ (hyperchromic effect). The INS and PHL's interaction absorbs a large amount of energy at a lower wavelength than PHL. It has been reported that molecular overlap can occur against small molecules with nitrogenous base groups in the DNA chain (Farajzadeh-Dehkordi et al. 2020). The fluorescence emission spectra overlap with the absorbance spectra of the acceptor molecule. Possibility of energy transfer when the donor-acceptor distance is less than $8 \mathrm{~nm}$ or $80 \AA$ (Hu and Liu 2015).
Ligands have higher transition energy than protein which is read as a higher molar absorption coefficient $(\varepsilon)$ value of PHL, each PHL and INS have the $\varepsilon$ value 7092 and $1389 \cdot \mathrm{M}^{-1} \cdot \mathrm{cm}^{-1}$ (Table 1). An interaction between INS and PHL can be proposed based on spectrum and the $\varepsilon$ value. The largest $\varepsilon$ value was obtained at the mole ratio of 1:0.05 (PHL: INS), which was $159,040 \cdot \mathrm{M}^{-1} \cdot \mathrm{cm}^{-1}$. The lowest $\varepsilon$ value was found in the ratio $1: 1$ is $9396 \cdot \mathrm{M}^{-1} \cdot \mathrm{cm}^{-1}$. The higher the mole ratio of INS, the higher the absorbance, but the weaker the ability to capture light or the smaller the molar absorption coefficient. In this study, the maximum absorbance of PHL was 285 nm (Fig. 1a). Similarly, the optimum PHL absorption was detected at a wavelength of $285 \mathrm{~nm}$ (Chen et al. 2020). The optimum absorption peak followed the PHL trend than INS, an indication that the increase in absorbance of the INS-PHL mixture is dominantly influenced by PHL even though the PHL mole ratio is constant. Albumin binding with ligands was conditioned with low ligand concentration but a high ligand-albumin ratio. Ligand molecules can associate with low affinity (Tang et al. 2006). Figure $1 \mathrm{~b}$ showed that INS-PHL absorption increased with increasing PHL concentration. 
Table 1 The molar absorption coefficients $(\varepsilon)$ of PHL and INS

\begin{tabular}{|c|c|c|c|c|}
\hline $\begin{array}{l}\text { Mole ratio } \\
\text { (PHL: INS) } \\
\end{array}$ & Concentration (M) & Absorbance & Maximum absorption wavelength & $\varepsilon\left(M^{-1} \cdot \mathrm{cm}^{-1}\right)$ \\
\hline 1:0.05 & $2.5 \times 10^{-6}$ & 0.3976 & 285 & 159,040 \\
\hline 1:0.1 & $5.0 \times 10^{-6}$ & 0.4166 & 285 & 83,320 \\
\hline 1:0.5 & $2.5 \times 10^{-5}$ & 0.4215 & 284 & 16,860 \\
\hline $1: 1$ & $5.0 \times 10^{-5}$ & 0.4698 & 283 & 9396 \\
\hline PHL $5.0 \times 10^{-5} \mathrm{M}$ & $5.0 \times 10^{-5}$ & 0.3600 & 285 & 7092 \\
\hline INS $5.0 \times 10^{-5} \mathrm{M}$ & $5.0 \times 10^{-5}$ & -0.0741 & 285 & 1389 \\
\hline
\end{tabular}

The higher the PHL ratio, the larger the wavelength shift of the shape of peak and maximum absorbency of INS.

Protein absorbance measurements have been carried out at room temperature conditions and normal $\mathrm{pH}$ to mimic protein's normal condition (Nienhaus and Nienhaus 2005). In two separate studies, it was found that insulin does not dissolve at normal $\mathrm{pH}$ but dissolves in the $\mathrm{pH}$ range 2-3 using $\mathrm{HCl}$ as a solvent (Gooch 2004; Sigma-Aldrich Co. 2014). The intrinsic fluorescence in insulin fibrils was recorded at $\mathrm{pH} 1.8$ and $\mathrm{pH}$ 7, which was different from normal protein. This study used $\mathrm{HCl}$ pH 2 as a solvent. The morphological review of insulin using TEM showed that insulin fluorescence was not entirely related to the morphological features of amyloid fibrils (Iannuzzi et al. 2017b).

\section{Fluorescence spectroscopy studies of the interaction between INS and PHL}

INS excitation observations have been carried out at a wavelength range of $200-500 \mathrm{~nm}$, and the optimum was at $276 \mathrm{~nm}$ (Correia et al. 2012). Excitation observations were carried out in the range of $400-500 \mathrm{~nm}$, and the optimum was at a wavelength of $440 \mathrm{~nm}$ (Iannuzzi et al. 2017b). In the present study, the strongest INS fluorescence signal was detected at a wavelength of $280 \mathrm{~nm}$
(Fig. 2) similar to Kierdaszuk's results (Kierdaszuk et al. 1995). Furthermore, the fluorescence spectrum was recorded at 298K conditions with a scanning range of 290 to $340 \mathrm{~nm}$ at a constant INS concentration and PHL as a quenching agent. INS fluorophore emissions were regulated in the range of 300-400 $\mathrm{nm}$, with a maximum emission at $340 \mathrm{~nm}$ (Iannuzzi et al. 2017b). The fluorescent intensity of insulin at a wavelength of about 303 $\mathrm{nm}$ decreased, widened, and produced a redshift (Soleymani et al. 2016). This phenomenon was found in the interaction of vitamin $\mathrm{E}$ with human insulin. The increase in vanillin concentration decreased the fluorescence intensity indicating that vanillin and INS had interactions (Iannuzzi et al. 2017b). In the present study, the same pattern was found (i.e., the addition of PHL caused a redshift from 305 to $317 \mathrm{~nm}$ ).

Three types of amino acids, namely tryptophan (Trp), tyrosine (Tyr), and phenylalanine (Phe), have different chromophores and can emit fluorescence in protein molecules (Yang et al. 2015). Trp has the strongest fluorescence intensity than Tyr, and Phe is the weakest. INS is composed of 51 amino acids, including 4 Tyr residues (A14, A19, B16, B26) and 3 Phe. This composition makes the two amino acid functional groups act as the main fluorescent in the INS molecule. Phe quantum is

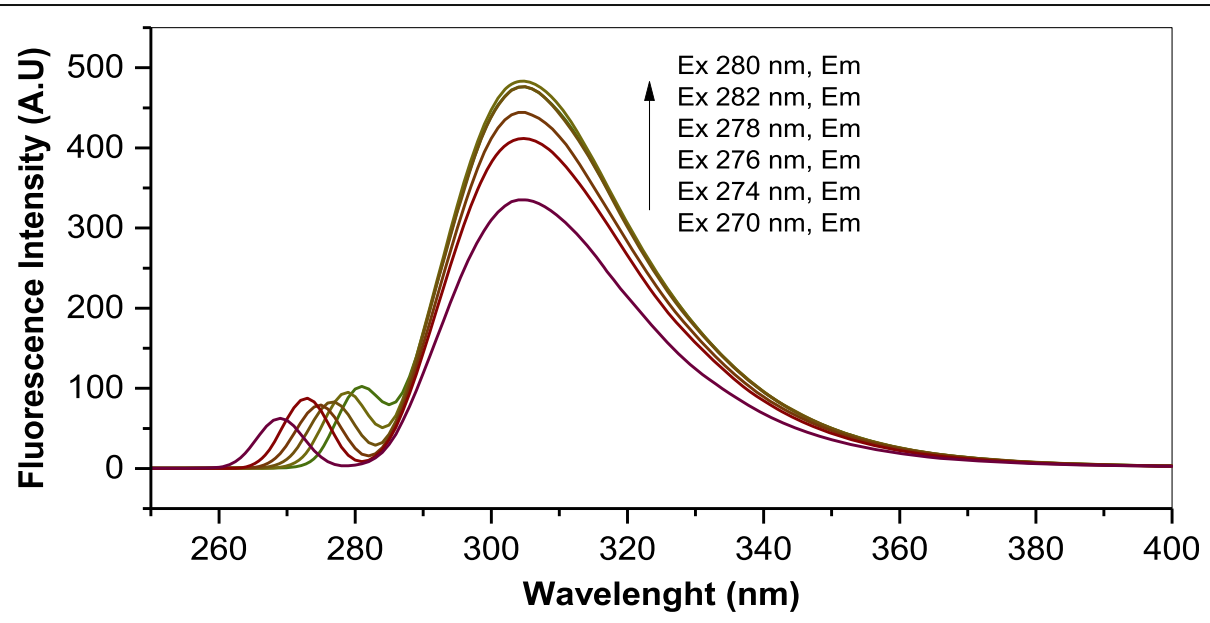

Fig. 2 The fluorescence intensity of INS in different excitation wavelength 
relatively low and has no Trp residue, making the Tyr residue responsible for INS's fluorescence properties. The binding of proteins with ligands can change amino acids through fluorophore interactions or quencher effects. The most noticeable changes observed were a reduction in fluorescent intensity and a shift in the spectrum (Soleymani et al. 2016). In the present study, PHL was used as a quenching agent and interacted at different ratios. Measurements were set with a wavelength of $280 \mathrm{~nm}$ at three temperatures, namely $288 \mathrm{~K}$, $298 \mathrm{~K}$, and $308 \mathrm{~K}$ (Figs. 3, 4, 5). Figures 3, 4, and 5 show that the maximum INS emission signal was observed at a wavelength of $305 \mathrm{~nm}$, indicating that temperature changes did not affect the INS emission signal.

Internal fluorescence effects (IFE) has been corrected by equations (Farajzadeh-Dehkordi et al. 2020; HashemiShahraki et al. 2020; Wani et al. 2020b).

$$
F_{\text {corr }}=F_{\text {obs }} \times e^{\frac{A_{\text {ex }}+A_{\text {em }}}{2}}
$$

$F_{\text {corr }}$ and $F_{\text {obs }}$ are the correction and observation of fluorescence intensities, respectively. $A_{\mathrm{ex}}$ and $A_{\mathrm{em}}$ are the wavelengths of excitation and emission, respectively. The $A_{\mathrm{ex}}$ and $A_{\mathrm{em}}$ were $280 \mathrm{~nm}$ and $305 \mathrm{~nm}$. The fluorescence intensity ratio $\left(F_{0} /{ }_{F}\right)$ at different temperatures was also calculated. $F_{0}$ and $F$ are ascribed as the fluorescence intensity of INS before and after the addition of quencher (PHL), respectively. The highest ratio of 8.24 was obtained at $288 \mathrm{~K}$, followed by 7.78 at $298 \mathrm{~K}$. When the temperature increased to $308 \mathrm{~K}$, it resulted in the lowest ratio of 7.52. These results suggest that the fluorescence intensity ratio $F_{0} /_{F}$ decreases with the increased temperature.

Figure 6 shows the plotting curve of the concentration of PHL against the fluorescence intensity. It can be observed that the quenching effect occurs at the three temperatures. The addition of PHL causes changes in the microenvironment surrounding the INS's amino acid residues, resulting in a decrease in INS's fluorescence intensity, which indicates an interaction between INS and PHL. The mechanism of action from these interactions can be further judged through the Stern-Volmer equation.

\section{The influence of PHL on the fluorescence intensity of Tyr} It has been proposed that the fluorescence properties of INS mainly come from Tyr residues (A14, A19, B16, B26). Therefore, the fluorescence properties of Tyr were also studied in the absence and presence of PHL (Fig. 7). The spectrum was recorded at an excitation wavelength ranging from 280 to $400 \mathrm{~nm}$ and a temperature of 298 $\mathrm{K}$, while the Tyr residues were measured at $305 \mathrm{~nm}$. Figure 7 shows that the addition of different PHL concentrations can change the fluorescence intensity of $\mathrm{Tyr}$ significantly. As the concentration of PHL increases, the fluorescence intensity of Tyr weakens and produces a redshift. This result is similar to the fluorescence quenching experiment of INS by PHL. It confirms that PHL can change Tyr residues' surrounding environment and decrease fluorescence intensity.

Determination of binding constant of INS-PHL interaction INS's quenching effect by PHL has been known as static quenching and accompanied by dynamic quenching, indicating interactions and the formation of complexes between INS and PHL. Static quenching takes into account the formation of INS-PHL interaction. The researchers (Lakowicz 1999; Zhang et al. 2008; Gentili et al. 2008; Shi et al. 2013; Shi et al. 2015; Hashemi-Shahraki et al. 2020) explained that the binding constant $\left(K_{a}\right)$ value and the number of binding sites $(n)$ between biomacromolecules and small molecules can be determined by Eq. 1 .

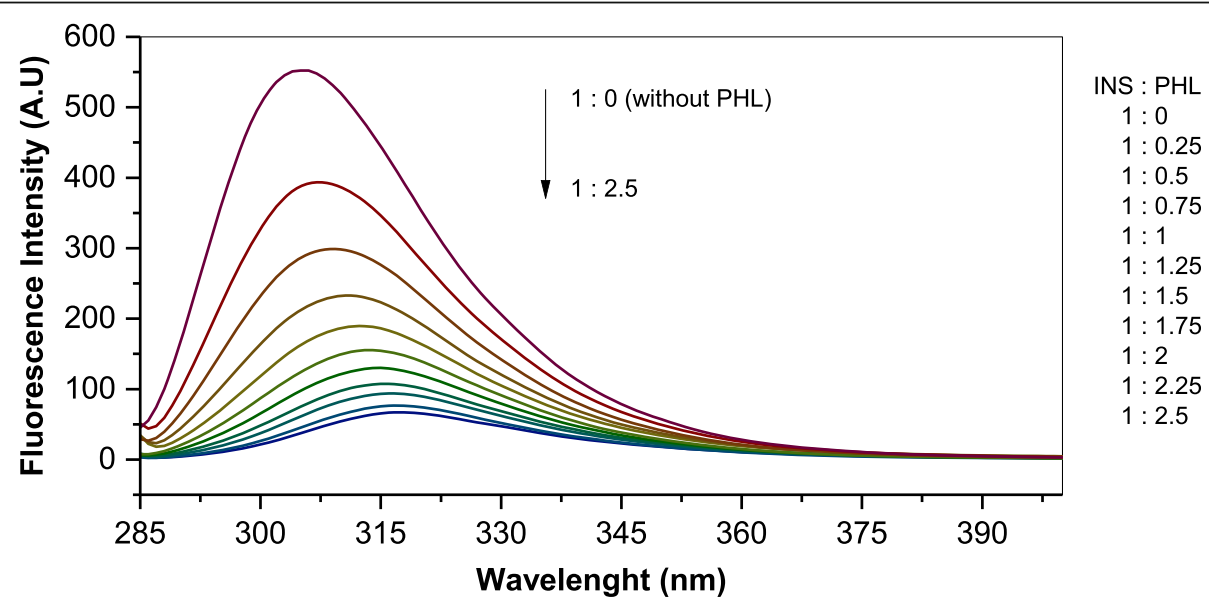

Fig. 3 The fluorescence intensity of INS and PHL in $288 \mathrm{~K}$ 


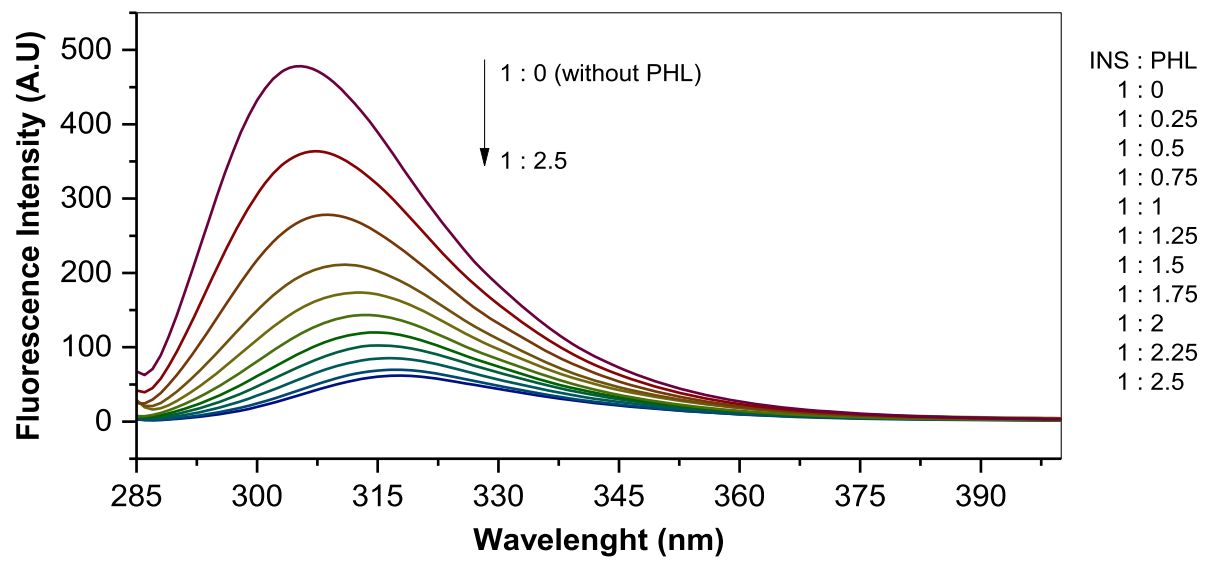

Fig. 4 The fluorescence intensity of INS and PHL in $298 \mathrm{~K}$

$$
\log \left[\frac{F_{0}-F}{F}\right]=\log K_{a}+n \log [Q]
$$

$F_{0}$ : Fluorescence intensity without adding quencher

$F$ : Fluorescence intensity with a particular concentration of quenching agent

$K_{a}$ : Binding constant of two molecules $\left(\mathrm{M}^{-1}\right)$

$n$ : Binding site of two molecules

$[Q]$ :The concentration of quenching agent $(\mu \mathrm{M})$

The $K_{a}$ values of the INS-PHL interaction were found to be $1.53 \times 10^{4}, 1.16 \times 10^{4}$, and $9.80 \times$ $10^{3} \mathrm{M}^{-1}$ at 288,298 , and $308 \mathrm{~K}$, respectively (Eq. 2). The calculated $K_{a}$ values indicate that INS and PHL are mutually binding, and the binding effect is relatively significant. Based on Table 2 , the $K_{a}$ values decreased with the increase of temperature. It means that INS and PHL's stability reduces at a higher temperature, similar to the observation by Lakowicz and Weber (1973). An increase in the temperature can decrease the binding constant and binding sites. This phenomenon occurred with NYS-pepsin binding. The reactions involved in its binding were exothermic (Hashemi-Shahraki et al. 2020). The binding sites $n$ were $1.2542,1.295$, and 1.3295 at the three measured temperatures. A binding site value of approximately 1 means that the binding site or region is single, usually located in a hydrophobic and low-affinity region (Le Han et al. 2009). These values confirm that there are binding regions between INS and PHL. The binding constant value was $10^{3}$ to $10^{4}$ in the temperature range of $298-310 \mathrm{~K}$. This value was a binding constant range of DNA pathways with small molecules. Based on this, the gefitinib bonds in ct-DNA have groove bonds (Shi et al. 2015). The same magnitude was also found in INS and PHL, which ranged from $10^{3}$ to $10^{4}$. Also, it was observed that the $n$ values decrease as the temperature decreases, which also proves that higher temperatures increased the INS-

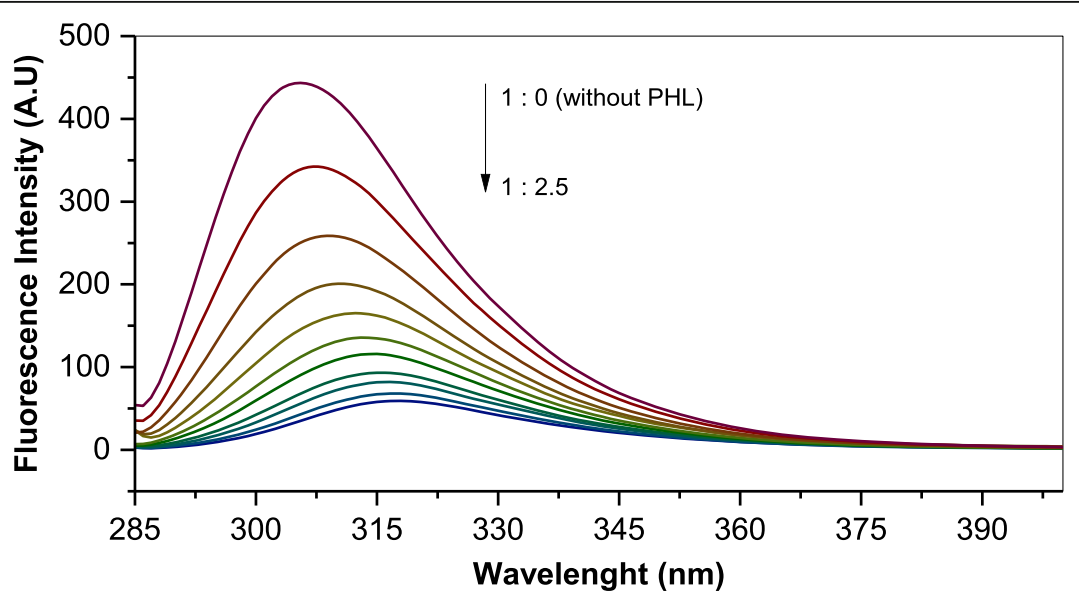

INS : PHL

$1: 0$

$1: 0.25$

$1: 0.5$

$1: 0.75$

$1: 1$

$1: 1.25$

$1: 1.5$

$1: 1.75$

$1: 2$

$1: 2.25$

$1: 2.5$

Fig. 5 The fluorescence intensity of INS and PHL in $308 \mathrm{~K}$ 


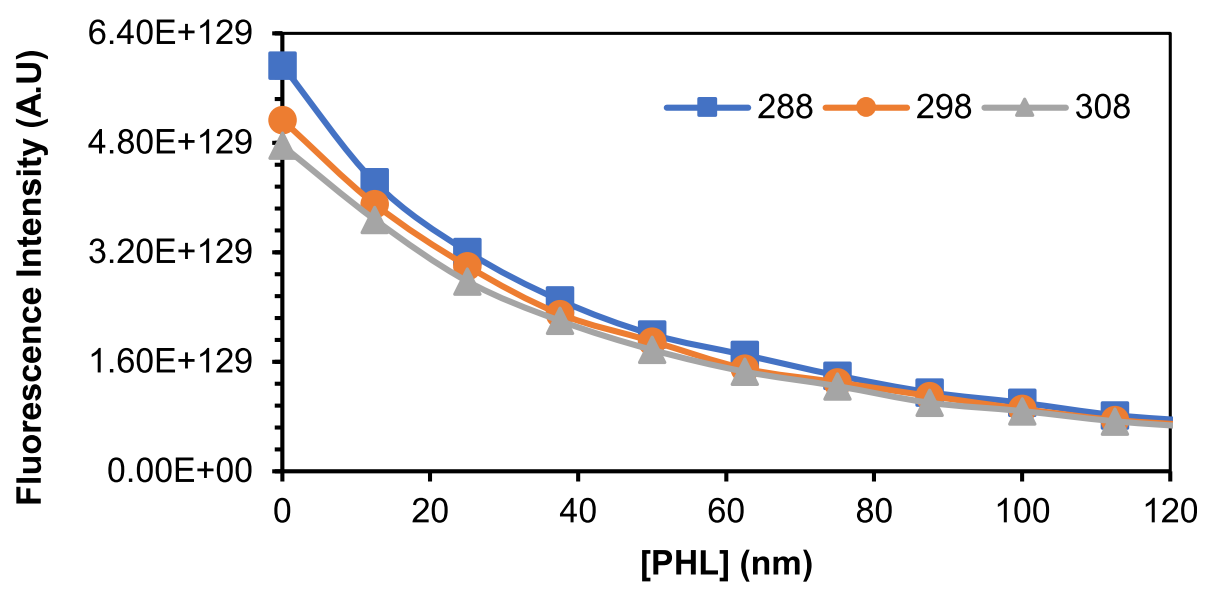

Fig. 6 The fluorescence intensity plotted of PHL at different temperatures

PHL interaction stability. Storing insulin at high temperatures can reduce its biological activity (Werdinius 1962).

\section{Thermodynamic parameters and interaction force of $\mathrm{PHL}$} and INS

Fluorescence spectroscopy has been used to explore macromolecules' thermodynamics, including proteins and nucleic acids (Eftink 2000). There are four main interaction forces between macromolecules and small organic molecules: hydrogen bonds, dispersion forces, hydrophobic force, and electrostatic attraction. The binding and interaction of the related proteins are usually caused by hydrophobic interaction and Van der Waals force (Ross and Subramanian 1981). The thermodynamic parameters of the reaction, such as enthalpy $\left(\Delta H^{0}\right)$ and entropy $\left(\Delta S^{0}\right)$, were calculated to determine the intermolecular force and the interaction between molecules (Ross and Subramanian 1981; Zhang et al. 2010; Hu and Liu 2015; Gummadi 2003). Both of these parameters can be calculated by the Van't Hoff equation (Eq. 3).

$$
\ln K_{a}=-\frac{\Delta H^{0}}{R T}+\frac{\Delta S^{0}}{R}
$$

$K_{a}$ : Binding constant of two molecules $\left(\mathrm{M}^{-1}\right)$

$T$ : Reaction temperature $(\mathrm{K})$

$R$ : Ideal gas constant $(8.314 \mathrm{~J} / \mathrm{mol} \cdot \mathrm{K})$

$\Delta H^{0}$ : Enthalpy change of chemical reaction $(\mathrm{J} / \mathrm{mol})$

$\Delta S^{0}$ : Entropy change of chemical reaction $(\mathrm{J} / \mathrm{mol} \cdot \mathrm{K})$

The calculated binding constant $K_{a}$ at three temperatures (Table 2) was used to calculate the thermodynamic parameters by plotting $1000 / T$ against $\ln K_{a}$ (Fig. 8). The slope and intercept of the graph ascribed as the thermodynamic parameters $\Delta H^{0}$ and $\Delta S^{0}$, respectively. According to Eq. 2, it can be determined that $\left.-\left(\Delta H^{0}\right) / R\right)$ is attributed to the slope and $\left(\Delta S^{0}\right) / R$ as the intercept. Free energy $\left(\Delta G^{0}\right)$ in the reaction process can be calculated through Eq. 4 (Hashemi-Shahraki et al. 2020; Shi et al. 2013; Shi et al. 2015):

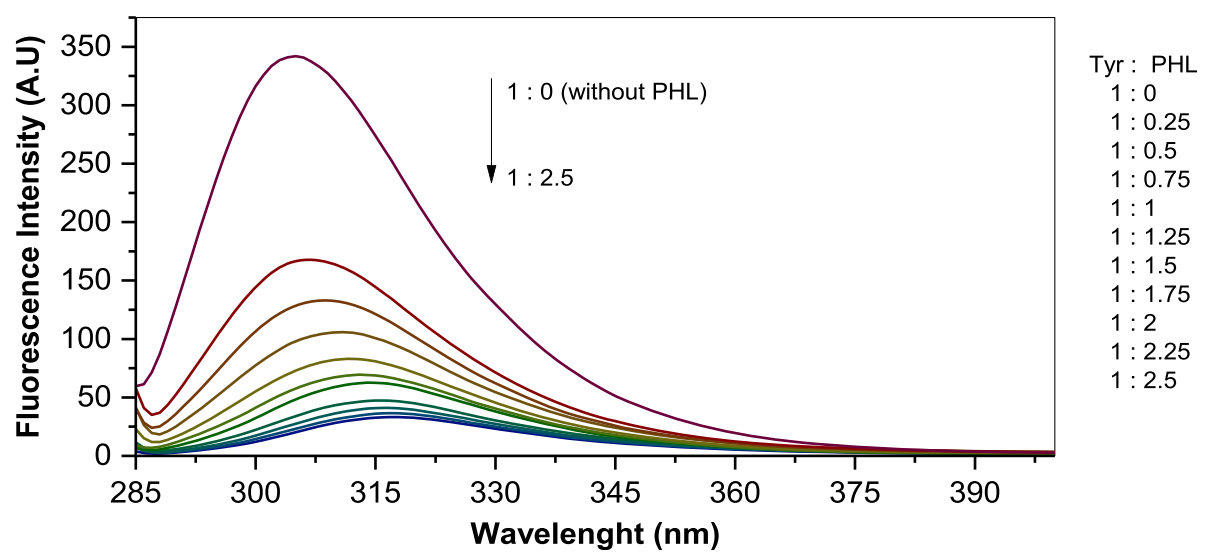

Fig. 7 The fluorescence intensity of Tyr by PHL in 298K 
Table 2 The binding constant $K_{a}$ value and the number of binding sites $n$ between PHL and INS

\begin{tabular}{llll}
\hline $\boldsymbol{T}(\mathrm{K})$ & $\boldsymbol{K}_{\boldsymbol{a}}\left(\mathrm{M}^{-\mathbf{1}}\right)$ & Number & $\boldsymbol{R}^{\mathbf{2}}$ \\
\hline 288 & $1.53 \times 10^{4}$ & 1.2542 & 0.994 \\
298 & $1.16 \times 10^{4}$ & 1.295 & 0.9977 \\
308 & $9.80 \times 10^{3}$ & 1.3295 & 0.9973 \\
\hline
\end{tabular}

$$
\Delta G^{0}=\Delta H^{0}-T \Delta S^{0}=-R T \ln K_{b}
$$

$\Delta G^{0}$ : Effective experiment produced when a system changes $(\mathrm{kJ} / \mathrm{mol})$

$T$ : Reaction temperature $(\mathrm{K})$

$\Delta H^{0}$ : The enthalpy changes of the chemical reaction $(\mathrm{kJ} / \mathrm{mol})$

$\Delta S^{0}$ : Entropy change of chemical reaction $(\mathrm{kJ} / \mathrm{mol} \cdot \mathrm{K})$

The relationship and the forces forming between two molecules can be explored when the thermodynamic parameters are obtained (Ross and Subramanian 1981; Gummadi 2003). The thermodynamic parameters $\left(\Delta H^{0}\right.$ and $\Delta S^{0}$ ) values can determine the type of interactions between molecules, and it is mainly divided into three types:

When $\Delta H^{0}>0, \Delta S^{0}>0$ is the hydrophobic force;

When $\Delta H^{0}<0, \Delta S^{0}<0$ is hydrogen bond and dispersion forces.

When $\Delta H^{0} \cong 0, \Delta S^{0}<0$ is electrostatic gravity.

Through the summary in Table 3 , it can be observed that both of the thermodynamic parameters $\Delta H^{0}$ were negative, $\Delta S^{0}$ were obtained positive $(-16.514 \mathrm{~kJ} / \mathrm{mol}$ and $22.65 \mathrm{~J} / \mathrm{mol} \cdot \mathrm{K})$. Based on three types of molecular interactions, INS and PHL intrigue can occur by hydrophobic force, hydrogen bond, and disperse forces at temperatures of $288 \mathrm{~K}, 298 \mathrm{~K}$, and $308 \mathrm{~K} . \Delta H^{0}$ and $\Delta S^{0}$ can affect protein denaturation (Soleymani et al. 2016).
Soleymani et al. reported the results of the differential analysis calorimetric scanning (DSC) of human insulin. Denaturation occurred at a temperature of $73.1{ }^{\circ} \mathrm{C}$ at $\Delta G^{0} 8.89 \mathrm{kcal} / \mathrm{mol}$. A positive $\Delta S^{0}$ indicates a hydrophobic interaction between celecoxib and human albumin, while a negative $\Delta H^{0}$ is ascribed to the interaction dominated by hydrogen bonds (Seedher and Bhatia 2006). Positive entropy is evidence of hydrophobic interactions; electrostatic interactions are also indicated by positive entropy and negative enthalpy (Tang et al. 2006). Hydrophobic interactions occur due to water molecules' presence around the ligands and proteins (Ding et al. 2009). A significant contribution to the $\Delta H^{0}$ and $\Delta S^{0}$ proteins comes from electrons' delocalization in their aromatic rings (Ross and Subramanian 1980). The free energy between the two molecules at three different temperatures $(288 \mathrm{~K}, 298 \mathrm{~K}$, and $308 \mathrm{~K})$ was calculated and was $23.04,-23.26$, and $-23.49 \mathrm{~kJ} / \mathrm{mol}$. It can be found that $\Delta G^{0}$ at three different temperatures were also negative, indicating the interaction between INS and PHL occurred in a spontaneous reaction (Ross and Subramanian 1981).

\section{Quenching effect of PHL on INS}

The reduction in fluorescence intensity is called the quenching effect. This effect can occur through dynamic quenching mechanisms, static quenching, or both methods. Dynamic quenching fluorescence occurs when light collides with other molecules in a solution. High temperatures increase collisions among molecules so that the dynamic quenching constant increases with the increase in temperature. A static quenching mechanism occurs. When fluorescent and quenching agents form complexes, the closer the molecules' distance becomes, causing the fluorescence intensity to decrease. Static quenching occurs in the ground state, independent of

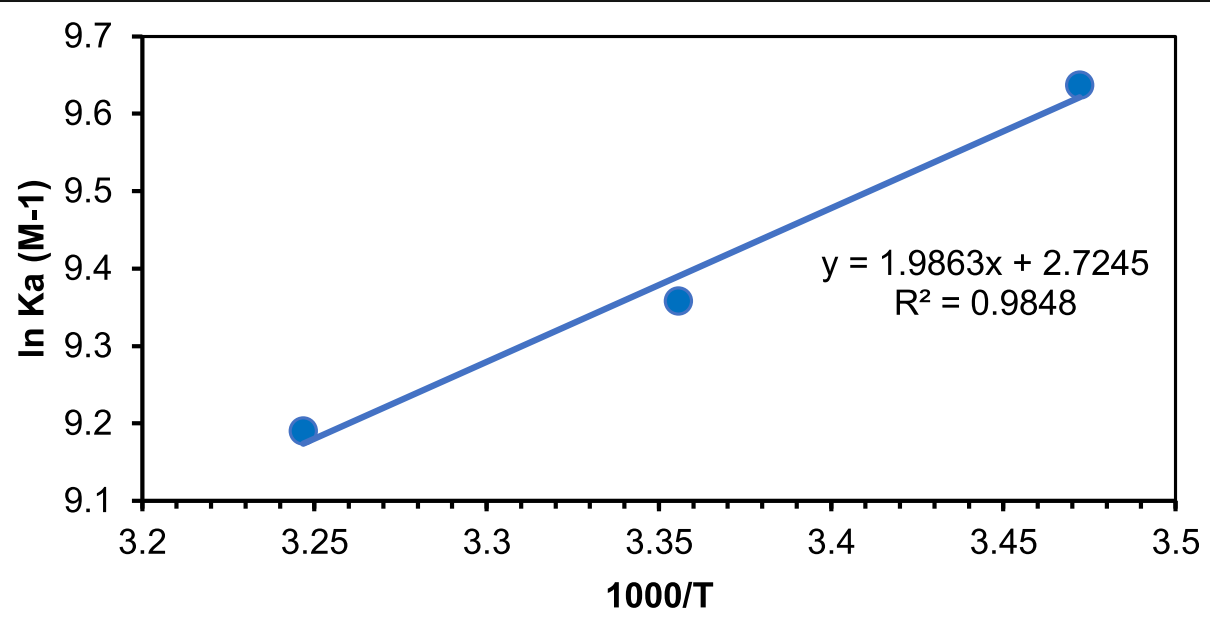

Fig. $8 K_{a}$ values of INS-PHL Interaction at three temperatures 
Table 3 The thermodynamic parameters of INS and PHL reaction

\begin{tabular}{llll}
\hline $\mathrm{T}(\mathrm{K})$ & $\boldsymbol{\Delta} \boldsymbol{H}^{\mathbf{0}}(\mathrm{kJ} / \mathrm{mol})$ & $\Delta \boldsymbol{S}^{\mathbf{0}}(\mathrm{J} / \mathrm{mol} \cdot \mathrm{K})$ & $\Delta G^{\mathbf{0}}(\mathrm{kJ} / \mathrm{mol})$ \\
\hline 288 & -16.514 & 22.65 & -23.04 \\
298 & & & -23.26 \\
308 & & & -23.49
\end{tabular}

the effects of collision or diffusion. Complex stability and quenching strength weaken with increased temperature (Dangkoob et al. 2015; Lakowicz and Weber 1973; Ma et al. 2019). The Stern-Volmer equation can be used to calculate static and dynamic quenching parameters. $K_{D}$ is used in the dynamic quenching mechanism (Eq. 5) and $K_{S}$ in static quenching (Eq. 6). If the quenching mechanism is sweetened, and static coincides, a modification (Eq. 7) of the Stern-Volmer equation (Eq. 8) is used to get the quenching constant. When the quenching agent's concentration increases, the fluorophore is quenched both statically and dynamically (Lakowicz and Weber 1973). Generally, the higher temperature causes a faster diffusion, which leads to a large amount of collision quenching. This condition can dissociate a weaker binding among molecules and indirectly cause a weak static quenching.

$$
\begin{aligned}
& \frac{F_{0}}{F}=1+k_{q} \tau_{0}[Q]=1+K_{\mathrm{D}}[Q] \\
& \frac{F_{0}}{F}=1+K_{s}[Q]=1+k_{q} \tau_{0}[Q] \\
& K_{s}=k_{q} \tau_{0} \\
& \frac{F_{0}}{F}=\left(1+K_{D}[Q]\right) e^{K_{s}[Q]}
\end{aligned}
$$

$F_{0}$ : Fluorescence intensity without adding quencher

$F$ : Fluorescence intensity with a specific concentration of quenching agent

$K_{D}$ : Stern-Volmer fluorescence dynamic quenching constant $\left(\mathrm{M}^{-1}\right)$

$K_{s}$ : Stern-Volmer fluorescence static quenching constant $\left(\mathrm{M}^{-1}\right)$

$k_{q}$ : Stern-Volmer fluorescence quenching rate constant $\left(\mathrm{M}^{-1} \cdot \mathrm{s}^{-1}\right)$

$\tau_{0}$ : The average lifetime of fluorescent molecules without adding quencher (s)

$[Q]$ : Concentration of quenching agent $(\mu \mathrm{M})$
The Stern-Volmer linear relationship can be obtained by plotting the concentration of quencher $[Q]$ versus the ratio of the fluorescence intensity before and after addition of quencher $\left(F_{0} / F\right)$. The linear curve indicates the occurrence of dynamic quenching (Kathiravan et al. 2009). In this study, the Stern-Volmer linear relationship was determined from three temperatures of 288, 298, and $308 \mathrm{~K}$ (Fig. 9). Figure 9 shows a nonlinear curve between the concentration of PHL $[Q]$ and fluorescence intensity ratio $\left(F_{0} /{ }_{F}\right)$, indicating the quenching mechanisms are both dynamic and static quenching. This result suggests that PHL's quenching effect to INS refers to the intermolecular collision and the static quenching around the tyrosine residue with the fluorescent emitting group. It is also observed that a higher temperature affects the strength of the complexes' binding and leads to the weakening of the static quenching. Figure 9 also depicts the relatively linear relationship between the fluorescence intensity ratio $\left(F_{0} /_{F}\right)$ and increased temperature. Since the reaction between PHL and INS involves both static and dynamic quenching, the SternVolmer curve can be corrected with Eq. 7 and both the dynamic $\left(K_{D}\right)$ and static $\left(K_{s}\right)$ quenching constants can be calculated.

Table 4 displays dynamic quenching constant $K_{D}$ of INS-PHL complexes at three temperatures $1.18 \times 10^{6}$, $1.13 \times 10^{6}$, and $1.12 \times 10^{6} \mathrm{M}^{-1}$. It can be noted that the $K_{D}$ value decreases with the increase in temperature, signifying that PHL's quenching effect to INS is related to temperature. This result is the opposite of the static quenching constant $K_{S}$ that increases as the temperature increases. The quenching rate constant $k_{q}$ can be calculated by substituting the $K_{D}$ and $\tau_{0}$ value to Eq. 7 . The $\tau_{0}$ is described as the average fluorescence of biomolecules without a quenching agent. The $\tau_{0}$ value of INS has been reported to be $1.4 \times 10^{-9} \mathrm{~s}$ (Zhang et al. 2008).

The maximum dynamic quenching rate constant caused by a dynamic quenching from macromolecules and quenching agent was $2.0 \times 10^{10} \mathrm{M}^{-1} \cdot \mathrm{s}^{-1}$ (Blatt et al. 1986; Gentili et al. 2008). In the present study, the quenching rate constants at the three temperatures of $288 \mathrm{~K}, 298 \mathrm{~K}$, and $308 \mathrm{~K}$ were found to be $1.17 \times 10^{13}$, $1.16 \times 10^{13}$, and $1.14 \times 10^{13} \mathrm{M}^{-1} \cdot \mathrm{s}^{-1}$, respectively (Table 4). This result is greater than the maximum dynamic quenching rate constant caused by dynamic quenching. Thus, it can be proposed that the quenching effect of PHL on INS is mainly a static quenching accompanied by a dynamic quenching, and there is also an interaction between the two molecules. The formation of a complex shows the possibility of phloretin inducing the regional configuration changes in insulin. 


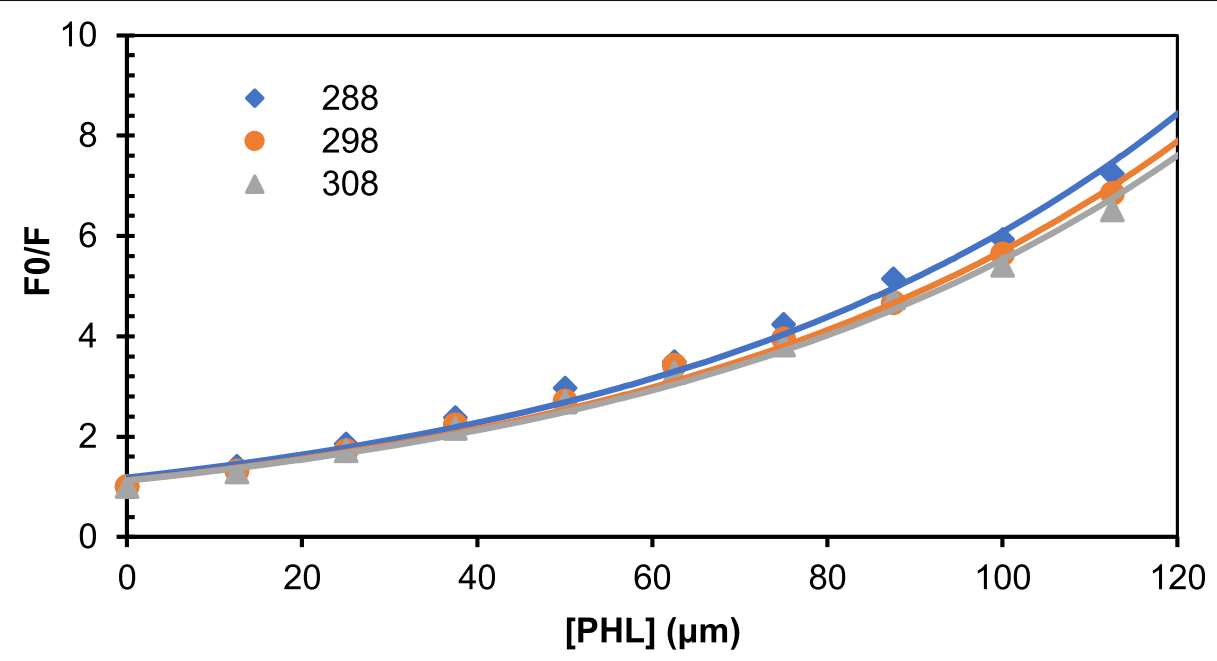

Fig. 9 The Stern-Volmer linear of PHL vs. INS under three different temperature conditions

\section{Circular dichroism (CD) spectropolarimeter to study the protein secondary structure changes}

The configuration of protein is considered significantly important to its therapeutic effect, and it is also applied to the secondary structure of insulin that can also explain its efficacy ( $\mathrm{Li}$ et al. 2012). CD spectropolarimeter is one of the best methods to explore the secondary structure of proteins (Greenfield 2007). Many studies have used this method to explore the secondary structure of insulin. In the present study, a CD spectropolarimeter was used to investigate the interaction between PHL and INS. It can be observed that before the addition of PHL, INS has two negative signals approximately at wavelengths of 210 and $220 \mathrm{~nm}$ (Fig. 10). These two negative signal peaks can be read as the characteristic peaks of $\alpha$-helix in the protein's secondary structure.

In observing insulin interaction with the surfactant, $\alpha$ helix polarization was detected at 209 and $222 \mathrm{~nm}$ (Pirhaghghi et al. 2015). The $\alpha$-helix content increased after the addition of surfactants, while the $\beta$-structure and random coil content decreased. It shows that the surfactants changed the second insulin level structure (Wang et al. 2009). A negative signal trough appeared at a wavelength of $209 \mathrm{~nm}$, and the shoulder peak occurred at about $225 \mathrm{~nm}$. The ratio of $\alpha$-helix was $20-21 \%$, and

Table 4 the fluorescence quenching constant $\left(K_{D}\right)$ and the fluorescence quenching rate constant $k_{q}$ of $\mathrm{PHL}$ and INS complex at three different temperatures

\begin{tabular}{llll}
\hline $\boldsymbol{T}(\mathrm{K})$ & $\boldsymbol{K}_{\boldsymbol{D}}\left(\mathbf{M}^{-1}\right)$ & $\boldsymbol{k}_{\boldsymbol{q}}\left(\mathbf{M}^{-\mathbf{1}} \cdot \mathbf{s}^{-\mathbf{1}}\right)$ & $\boldsymbol{K}_{\boldsymbol{S}}\left(\mathbf{M}^{-1}\right)$ \\
\hline 288 & $1.18 \times 10^{6}$ & $1.17 \times 10^{13}$ & $1.64 \times 10^{4}$ \\
298 & $1.13 \times 10^{6}$ & $1.16 \times 10^{13}$ & $1.62 \times 10^{4}$ \\
308 & $1.12 \times 10^{6}$ & $1.14 \times 10^{13}$ & $1.60 \times 10^{4}$ \\
\hline
\end{tabular}

the ratio of $\beta$-sheet was $26-28 \%$. This result confirms the nano-coating made of alginate and chitosan ( $\mathrm{Li}$ et al. 2012). The negative signal's intensity was a slight decrease at 200 to $230 \mathrm{~nm}$ on the interaction between vitamin D3 and human insulin. It suggests that the structural compactness and stability of protein $\alpha$-helix were reduced. Simultaneously, the interaction of vitamin $\mathrm{E}$ and human insulin leads to a significant increase in this wave range's negative signal intensity. It also reflects the structural compactness and stability of protein $\alpha$ helix (Soleymani et al. 2016).

The signal intensity of INS increased in the presence of PHL without any displacement. It indicates that INS interacted with PHL to form a complex and changed the INS's secondary structure. This condition increased the $\alpha$-helix content and enhanced its structural stability (Derewenda et al. 1989; Soleymani et al. 2016; Li et al. 2012). Interaction between protein and ligand can slow down proteins' aggregation to stabilize the protein structure (Gancar et al. 2020). This result has been used in $\mathrm{N}$ SELCON 3 software designed by Sreerama and Woody to confirm the protein's secondary structure content.

Table 5 shows that when PHL concentration increases, the proportion of $\alpha$-helix content in INS also increases. This result also proves that the addition of PHL can change the secondary structure of INS and enhance its structural stability. The induction of phloretin increased Peroxisome Proliferator's activity activated Receptor- $\gamma$ (PPAR- $\gamma$ ), which reduced and enhanced blood sugar. Insulin sensitivity can indirectly improve insulin resistance and reduce the possibility of suffering from metabolic diseases. The author studied oral phloretin therapy on diabetic mice to observe whether phloretin therapy would affect the mice's glucose balance (Shu et al. 2014). It was found that food consumption increased significantly within 2 to 5 


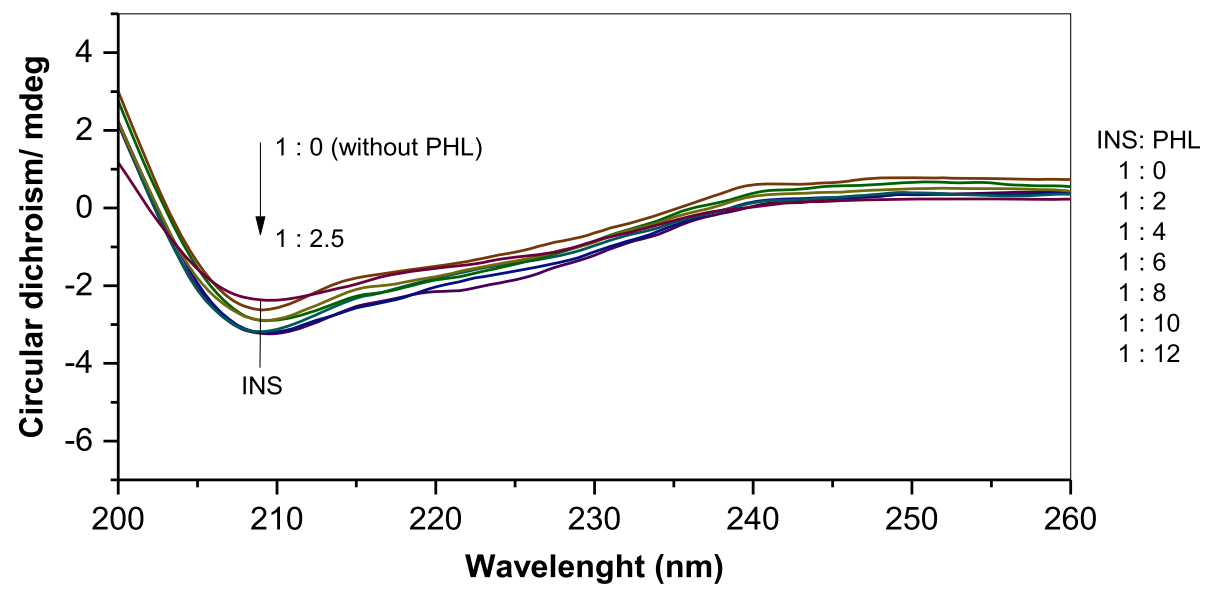

Fig. 10 The circular dichroic spectrum of INS with different concentrations of PHL, $T=298 \mathrm{~K}$

weeks and significantly reduced blood sugar levels, improved glucose tolerance, and reduced serum cholesterol by $20 \%$. Alsanea et al. (2017) used phloretin injections to treat rats fed on a high-fat diet. The author analyzed the serum concentration and found that glucose concentration, glucose tolerance, insulin resistance test, and fasting serum insulin concentration are better than those of untreated mice. This result also confirms that phloretin does improve the glucose content and insulin resistance of mice fed a high-fat diet.

\section{Molecular docking analysis}

Molecular docking is a computational method used to describe the interaction of protein molecules with their ligands. The interaction of proteins with ligands can only occur if the protein's binding site with these ligands is suitable. The ligand molecule's functional groups may be in an adequate position from their partners' amino acids. Regions that have low energy can be predicted as binding sites. Binding site prediction can show the possible structure configurations, or poses of protein subunits, how these subunits can be docked (Guo et al. 2012). Figure 11a shows the binding site of the interaction of phloretin and insulin in three-dimensional. The electrostatic quantization of insulin surfaces shows the interaction with PHL occurs in the contour range of +4.87 $\mathrm{kT} / \mathrm{e}$ to $-4.87 \mathrm{kT} / \mathrm{e}$, equivalent to $2.885 \mathrm{kcal} / \mathrm{mol}$ to $2.885 \mathrm{kcal} / \mathrm{mol}$. The aliphatic carbon interaction has an energy level contour of $5 \mathrm{kcal} / \mathrm{mol}$, and the hydrogen bond interaction level contour is $-0.5 \mathrm{kcal} / \mathrm{mol}$ (Seeliger and De Groot 2010). The affinity energy of INS-PHL is - $6.2 \mathrm{kcal} / \mathrm{mol}$. Based on this, the interactions that occur are hydrogen bond interactions. This is supported by Fig. 11b, which shows the hydrogen bond interaction between PHL and INS chain A, the binding residues on Tyr14 (tyrosine) and Glu17 (glutamic acid). Hydrophobic interactions occur in Tyr14 and Leu13 (leucine). The presence of water molecules in the environment affected the INS-PHL interaction. The study results on thermal, molecular dynamic simulation showed that curcumin interaction with trypsin was unstable and flexible. It can be seen from the hydrophobic interaction more than hydrogen bonding. The Ligplot plot shows the binding

Table $\mathbf{5}$ The ratio of secondary structure between INS and different concentrations of PHL

\begin{tabular}{lllll}
\hline INS:PHL & a-Helix (\%) & $\beta$-turn and others (\%) & Random coil & Total (\%) \\
\hline $1: 0$ & 22 & 38 & 40 & 100 \\
$1: 2$ & 34 & 36 & 30 & 100 \\
$1: 4$ & 37 & 36 & 28 & 101 \\
$1: 6$ & 39 & 38 & 27 & 100 \\
$1: 8$ & 41 & 32 & 28 & 101 \\
$1: 10$ & 41 & 28 & 31 & 100 \\
$1: 12$ & 41 & 35 & 25 & 101 \\
\hline
\end{tabular}



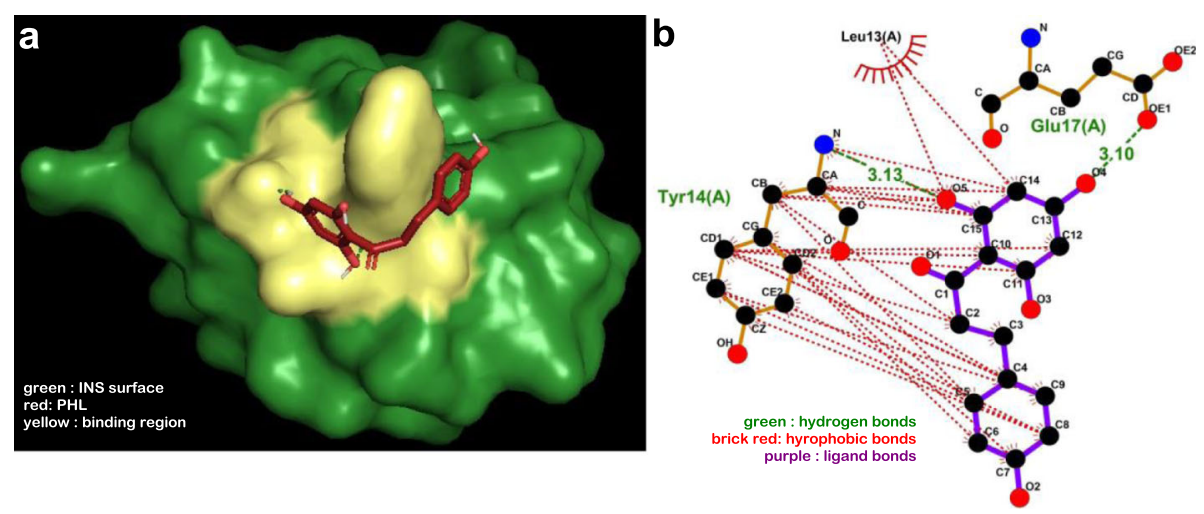

Fig. $11 \mathrm{PHL}$ and INS interaction by molecular docking. a the surface of INS. b LigPlot diagram

site of the $\alpha$-Chy bound to L-Cys, its energy affinity $4.32 \mathrm{kcal} / \mathrm{mol}$ so that the interaction takes place spontaneously (Rajabi et al. 2019).

Thus, the molecular docking illustration can strengthen the previous data. In the study of PHL-INS interactions, $\Delta H^{0}$ value showed a negative value, meaning that the two molecules' interaction was exothermic (released energy). The bonds formed between INS-PHL are hydrogen bonds. The amount of gibs energy is correlated with the interaction events that occur. PHL interaction on INS has a negative $\Delta G^{0}$. It shows that INS interaction as a protein and PHL molecules (as ligands) occurs spontaneously, and the two molecules are close together. When $\Delta G^{0}$ is negative, observations show that the distance between curcumin and some trypsin residues is close (Rajabi et al. 2019). The close interaction between the ligand and the protein, which occurs when $\Delta G^{0}$ is negative. Molecule L-Met is bound to the enzyme through hydrogen bonds, Van der Waals, and partially electrostatic interactions (Asgharzadeh et al. 2019). The CD spectropolarimeter results on the PHL-INS interaction showed that the intensity and stability of the $\alpha$ helix increased with increasing the PHL mole ratio. PHL interacts with $\alpha$-helix INS chain A compared with sheets; the main role of $\alpha$-helix was to improve conformational order. The percent of $\beta$-turn, the random coil that has been known to increase, and the binding site in the fluorescent analysis was equal to 1 ; thermodynamic parameters such as $\Delta H^{0}, \Delta S^{0}$, and $\Delta G^{0}$ have been calculated, and the type of interaction that occurred between chymotrypsin after binding to curcumin was Van der Waals (Farhadian et al. 2019). Based on thermodynamic studies, bovine trypsin interaction with curcumin was hydrogen bonds and Van der Waals (Rajabi et al. 2019). The Van der Waals bond is an electrostatic interaction, a strong Van der Waals bond between two molecules can prevent desorption (Keil and Mayer 2013). One of the insulin monomers interacts with other insulin monomers in Van der Waals force. Many amino acids are involved in the dimerization process (Correia et al. 2012). Perform molecular docking using AutoDock MGL Tools, AutoDock Vina, Pymol visualization tool, and LigPlot ${ }^{+}$version V.2.2.4. Simulations were performed on human insulin 3i40 obtained from the protein databank and phloretin molecules were drawn using ACD ChemSketch 2019.1.2.

\section{Conclusions}

UV/Vis spectra showed that the interaction between PHL and INS produced strong absorption at a wavelength of $282 \mathrm{~nm}$. The chromophore group of the aromatic amino acid ring has an absorption overlap with the PHL chromophore group. PHL and INS interactions occur at lower wavelengths with higher energies (blue shift and hyperchromic). The fluorescence analysis results showed that the excitation and emission occurred at a wavelength of $280 \mathrm{~nm}$ and $305 \mathrm{~nm}$. Temperature changes did not affect INS emissions. However, the interactions of PHL and INS caused a 305-317-nm redshift. Temperature affected the binding constant $\left(K_{a}\right)$ and the binding site $(n) . K_{a}$ decreased with increasing temperature and vice versa, but the binding site value increased. An indication that the stability of PHL and INS interactions is temperature dependent. The thermodynamic parameters such as enthalpy $\left(\Delta H^{0}\right)$ and entropy $\left(\Delta S^{0}\right)$ each have a value of $-16,514 \mathrm{~kJ} / \mathrm{mol}$ and $22.65 \mathrm{~J} /$ $\mathrm{mol} \cdot \mathrm{K}$. PHL and INS interaction formed hydrogen bonds and were hydrophobic. The free energy $\left(\Delta G^{0}\right)$ values at all temperatures $(288 \mathrm{~K}, 298 \mathrm{~K}$, and $308 \mathrm{~K})$ were 23.04, - 23.26, and - $23.49 \mathrm{~kJ} / \mathrm{mol}$, respectively. PHL and INS interactions took place spontaneously. The quenching effect was dynamic and static. $K_{D}$ values (1.18 $\times 10^{6}, 1.13 \times 10^{6}$, and $\left.1.12 \times 10^{6} \mathrm{M}^{-1}\right)$ were greater than those of $K_{S}\left(1.64 \times 10^{4}, 1.62 \times 10^{4}\right.$, and $\left.1.60 \times 10^{4} \mathrm{M}^{-1}\right)$. The higher the temperature, the less $K_{D}$ and $K_{S}$. The appearance of two negative signals on circular dichroism (CD) spectropolarimeter indicates the $\alpha$-helix structure. The addition of PHL has revealed the proportion of $\alpha$ - 
helix in the insulin structure. PHL could stabilize the structure of insulin, indicating that phloretin induced regional configuration changes in insulin. Phloretin and insulin interacted and formed a complex. Furthermore, the stabilization of phloretin and enhancement of the $\alpha$ helix structural configuration in insulin could be related to the phenomenon that phloretin can improve insulin resistance.

\section{Abbreviations}

INS: Insulin; PHL: Phloretin; UVNis: Ultraviolet-visible; CD: Circular dichroism; RTK: Tyrosine kinase receptor; nm: Nanometers; $\mathrm{HCl}$ : Hydrochloric acid; Tyr: Ltyrosine; DNA: Deoxyribonucleic acid; NH bonds: Nitrogen-Hydrogen bonds

\section{Acknowledgments}

The authors would like to thank the support of the Department of Applied Chemistry, Chaoyang University of Technology and the partial funding by the Ministry of Education, Taiwan

\section{Authors' contributions}

SY and ZWW carried out the experimental work, collected and analyzed the data, and drafted the manuscript. WJC conceived the idea, developed the theory, and supervised the research work. DCA revised the draft and made a substantial contribution to the revision of the manuscript. All authors agree to submit the revised manuscript

\section{Funding}

This research was funded by the Department of Applied Chemistry

Chaoyang University of Technology, and the Ministry of Education, Taiwan.

\section{Availability of data and materials}

The authors confirm that the data supporting this study's findings are available within the article and its supplementary materials.

\section{Declarations}

\section{Competing interests}

All authors declare no conflict of interest among them.

Received: 5 February 2021 Accepted: 20 July 2021

Published online: 09 August 2021

\section{References}

Alanazi MM, Almehizia AA, Bakheit AH, Alsaif NA, Alkahtani HM, Wani TA. Mechanistic interaction study of 5,6-Dichloro-2-[2-(pyridine-2yl)ethyl]isoindoline-1,3-dione with bovine serum albumin by spectroscopic and molecular docking approaches. Saudi Pharm J. 2019;27(3):341-7. https:// doi.org/10.1016/j.jsps.2018.12.001.

Al-Mehizia AA, Bakheit AH, Zargar S, Bhat MA, Asmari MM, Wani TA. Evaluation of biophysical interaction between newly synthesized pyrazoline pyridazine derivative and bovine serum albumin by spectroscopic and molecular docking studies. J Spectroscopy. 2019:1-12. https://doi.org/10.1155/2019/384 8670 .

Alsaif NA, Al-Mehizia AA, Bakheit AH, Zargar S, Wani TA. A spectroscopic, thermodynamic and molecular docking study of the binding mechanism of dapoxetine with calf thymus DNA. S Afr J Chem. 2020a;73:44-50. https://doi. org/10.17159/0379-4350/2020/v73a7.

Alsaif NA, Wani TA, Bakheit AH, Zargar S. Multi-spectroscopic investigation, molecular docking and molecular dynamic simulation of competitive interactions between flavonoids (quercetin and rutin) and sorafenib for binding to human serum albumin. Int J Biol Macromol. 2020b;165(Pt B): 2451-61. https://doi.org/10.1016/j.ijbiomac.2020.10.098.

Alsanea S, Gao M, Liu D. Phloretin prevents high-fat diet-induced obesity and improves metabolic homeostasis. AAPS J. 2017;19(3):797-805. https://doi. org/10.1208/s12248-017-0053-0.

Asgharzadeh S, Shareghi B, Farhadian S. Experimental and theoretical investigations on the interaction of L-methionine molecules with achymotrypsin in the aqueous solution using various methods. Int J Biol Macromol. 2019;131:548-56. https://doi.org/10.1016/j.jibiomac.2019.03.080.
Blatt E, Chatelier RC, Sawyer WH. Effects of quenching mechanism and type of quencher association on Stern-Volmer plots in compartmentalized systems. Biophys J. 1986;50(2):349-56. https://doi.org/10.1016/S0006-3495(86)83468-3.

Brown AE, Walker M. Genetics of Insulin Resistance and the Metabolic Syndrome. Curr Cardiol Rep. 2016;18(8):18(8). https://doi.org/10.1007/s11886-016-0755-4.

Chen J, Li Q, Ye Y, Huang Z, Ruan Z, Jin N. Phloretin as both a substrate and inhibitor of tyrosinase: inhibitory activity and mechanism. Spectrochim Acta A Mol Biomol Spectrosc. 2020;226:117642. https://doi.org/10.1016/j.saa.201 9.117642.

Chiti F, Dobson CM. Protein misfolding, functional amyloid, and human disease. Annu Rev Biochem. 2006;75(February 2006):333-66. https://doi.org/10.1146/a nnurev.biochem.75.101304.123901.

Correia M, Neves-Petersen MT, Jeppesen PB, Gregersen S, Petersen SB. UV-light exposure of insulin: pharmaceutical implications upon covalent insulin dityrosine dimerization and disulphide bond photolysis. PLoS One. 2012:712. www.plosone.org.

Dangkoob F, Housaindokht MR, Asoodeh A, Rajabi O, Rouhbakhsh Zaeri Z, Verdian DA. Spectroscopic and molecular modeling study on the separate and simultaneous bindings of alprazolam and fluoxetine hydrochloride to human serum albumin (HSA): with the aim of the drug interactions probing. Spectrochim Acta A Mol Biomol Spectrosc. 2015;137:1106-19. https://doi. org/10.1016/j.saa.2014.08.149.

Day RA, Underwood AL. Solutions manual quantitative analysis. Englewood Cliffs: Prentice Hall; 1991.

Derewenda U, Derewenda Z, Dodson EJ, Dodson GG, Reynoldst CD, Smith GD, et al. Phenol stabilizes more helix in a new symmetrical zinc insulin hexamer. Nature. 1989;338(6216):594-6.

Ding F, Huang J, Lin J, Li Z, Liu F, Jiang Z, et al. A study of the binding of C.I. Mordant Red 3 with bovine serum albumin using fluorescence spectroscopy. Dyes Pigments. 2009;82(1):65-70. https://doi.org/10.1016/j. dyepig.2008.11.003.

Dunn MF. Zinc-ligand interactions modulate assembly and stability of the insulin hexamer - a review. BioMetals. 2005;18(4):295-303. https://doi.org/10.1007/s1 0534-005-3685-y.

Eftink MR. Use of fluorescence spectroscopy as thermodynamics tool. Methods Enzymol. 2000;323:459-73. https://doi.org/10.1016/S0076-6879(00)23378-8.

Farajzadeh-Dehkordi M, Darzi S, Rahmani B, Farhadian S. A novel insight into the cytotoxic effects of Tephrosin with calf thymus DNA: experimental and in silico approaches. J Mol Liq. 2020;324:114728. https://doi.org/10.1016/j. molliq.2020.114728.

Farhadian S, Shareghi B, Asgharzadeh S, Rajabi M, Asadi H. Structural characterization of a-chymotrypsin after binding to curcumin: spectroscopic and computational analysis of their binding mechanism. J Mol Liq. 2019;289: 111111. https://doi.org/10.1016/j.molliq.2019.111111.

Fernandez GM, Lumbreras JM, Ordonez D. A thermodynamic approach to the binding mechanisms of cefotaxime to serum albumins. J Pharm Sci. 1993; 82(9):948-51. https://doi.org/10.1002/jps.2600820915.

Gancar M, Kurin E, Bednarikova Z, Marek J, Mucaji P, Nagy M, et al. Amyloid aggregation of insulin: an interaction study of green tea constituents. Sci Rep. 2020;10(1):1-12.

Gentili PL, Ortica F, Favaro G. Static and dynamic interaction of a naturally occurring photochromic molecule with bovine serum albumin studied by UV-visible absorption and fluorescence spectroscopy. J Phys Chem B. 2008;112(51):16793-801. https://doi.org/10.1021/jp805922g.

Gilg D, Riedl B, Zier A, Zimmermann MF. Analytical methods for the characterization and quality control of pharmaceutical peptides and proteins, using erythropoietin as an example. Pharm Acta Helv. 1996;71(6):383-94. https://doi.org/10.1016/S0031-6865(96)00048-9.

Gong Q, Haomiao Z, Haozhe Z, Chen C. Calculating the absolute binding free energy of the insulin dimer in an explicit solvent. RSC Adv. 2019;10(2):790-800.

Gooch JW. 2004. Molecular formula. http://www.mpbio.com.

Grasso EJ, Oliveira RG, Maggio B. Surface interactions, thermodynamics and topography of binary monolayers of insulin with dipalmitoylphosphatidylcholine and 1-palmitoyl-2-oleoylphosphatidylcholine at the air/water interface. J Colloid Interface Sci. 2016;464:264-76. https://doi. org/10.1016/j.jcis.2015.11.034.

Greenfield NJ. Using circular dichroism spectra to estimate protein secondary structure. Nat Protoc. 2007;1(6):2876-90.

Gummadi SN. What is the role of thermodynamics on protein stability? Biotechnol Bioprocess Eng. 2003;8(1):9-18. https://doi.org/10.1007/BF02932 892. 
Guo F, Li SC, Wang L, Zhu D. Protein-protein binding site identification by enumerating the configurations. BMC Bioinform. 2012;13(1).

Hashemi-Shahraki F, Shareghi B, Farhadian S. The interaction of Naphthol Yellow $S$ (NYS) with pepsin: insights from spectroscopic to molecular dynamics studies. Int J Biol Macromol. 2020;165(Pt B):1842-51. https://doi.org/10.1016/j. ijbiomac.2020.10.093.

Hu T, Liu Y. Probing the interaction of cefodizime with human serum albumin using multi-spectroscopic and molecular docking techniques. J Pharm Biomed Anal. 2015;107:325-32. https://doi.org/10.1016/j.jpba.2015.01.010.

lannuzzi C, Borriello M, Irace G, Cammarota M, Di Maro A, Sirangelo I, et al. Vanillin affects amyloid aggregation and non-enzymatic glycation in human insulin. Sci Rep. 2017a;7(1) www.nature.com/scientificreports.

Iannuzzi C, Borriello M, Portaccio M, Irace G, Sirangelo I. Insights into insulin fibril assembly at physiological and acidic ph and related amyloid intrinsic fluorescence. Int J Mol Sci. 2017b;18(12).

Kachooei E, Moosavi-Movahedi AA, Khodagholi F, Mozaffarian F, Sadeghi P, HadiAlijanvand $\mathrm{H}$, et al. Inhibition study on insulin fibrillation and cytotoxicity by paclitaxel. J Biochem. 2014;155(6):361-73. https://doi.org/10.1093/jb/mvu012.

Kandagal PB, Ashoka S, Seetharamappa J, Shaikh SMT, Jadegoud Y, ljare OB. Study of the interaction of an anticancer drug with human and bovine serum albumin: spectroscopic approach. J Pharm Biomed Anal. 2006;41(2): 393-9. https://doi.org/10.1016/j.jpba.2005.11.037.

Kathiravan $\mathrm{A}$, Anandan $\mathrm{S}$, Renganathan $\mathrm{R}$. Interaction of colloidal $\mathrm{TiO}_{2}$ with human serum albumin: a fluorescence quenching study. Colloids Surf A Physicochem Eng Asp. 2009;333(1-3):91-5. https://doi.org/10.1016/j.colsurfa.2 008.09.027.

Keil RG, Mayer LM. Mineral matrices and organic matter. 2nd ed: Elsevier Ltd.; 2013.

Kierdaszuk B, Gryczynski I, Modrak-Wojcik A, Bzowska A, Shugar D, Lakowicz JR. Fluorescence of tyrosine and tryptophan in proteins using one- and twophoton excitation. Photochem Photobiol. 1995;61(4):319-24. https://doi.org/1 0.1111/j.1751-1097.1995.tb08615.x.

Lakowicz JR. Principles of fluorescence spectroscopy. 3rd ed: Springer US; 1999. https://doi.org/10.1007/978-1-4757-3061-6.

Lakowicz JR, Weber G. Quenching of fluorescence by oxygen: a probe for structural fluctuations in macromolecules. Biochemistry. 1973;12(21):4161-70. https://doi.org/10.1021/bi00745a020.

Le Han X, Mei P, Liu Y, Xiao Q, Jiang FL, Li R. Binding interaction of quinclorac with bovine serum albumin: a biophysical study. Spectrochim Acta A Mol Biomol Spectrosc. 2009;74(3):781-7. https://doi.org/10.1016/j. saa.2009.08.018.

Li X, Qi J, Xie Y, Zhang X, Hu S, Xu Y, et al. Nanoemulsions coated with alginate/ chitosan as oral insulin delivery systems: preparation, characterization, and hypoglycemic effect in rats. Int J Nanomedicine. 2012;8:23-32.

Liefeng Z, Hui J, Wenjie Z, Lin W, Lingling S, Qiuyan W, et al. Improving the stability of insulin in solutions containing intestinal proteases in vitro. Int J Mol Sci. 2008;9(12):2376-87.

Ma Y, Chen AY, Xie XF, Wang XY, Wang D, Wang P, et al. Doping effect and fluorescence quenching mechanism of $\mathrm{N}$-doped graphene quantum dots in the detection of dopamine. Talanta. 2019;196(January):563-71. https://doi. org/10.1016/j.talanta.2019.01.001.

Matsuo K, Yonehara R, Gekko K. Improved estimation of the secondary structures of proteins by vacuum-ultraviolet circular dichroism spectroscopy. J Biochem. 2005;138(1):79-88. https://doi.org/10.1093/jb/mvi101.

Meti MD, Nandibewoor ST, Joshi SD, More UA, Chimatadar SA. Multispectroscopic investigation of the binding interaction of fosfomycin with bovine serum albumin. J Pharm Anal. 2015;5(4):249-55. https://doi.org/10.101 6/j.jpha.2015.01.004

Nienhaus K, Nienhaus GU. Probing heme protein-ligand interactions by UV/ visible absorption spectroscopy. Methods Mol Biol. 2005;305:215-42.

Pirhaghghi M, Saboury AA, Najafi F, Pourhosseini PS, Ghourchian H. Biophysical studies on the interaction of insulin with a cationic gemini surfactant. J Sci Islamic Rep Iran. 2015;26(2):105-15.

Rajabi M, Farhadian S, Shareghi B, Asgharzadeh S, Momeni L. Noncovalent interactions of bovine trypsin with curcumin and effect on stability, structure, and function. Colloids Surf B: Biointerfaces. 2019;183:110287. https://doi.org/1 0.1016/j.colsurfb.2019.06.017

Rodelo G, Citlaly, Reyes RGJAO. Molecular mechanisms of insulin resistance: an update. Medical Gazette Of Mexico Review Article Correspondence. Gac Med Mex. 2017;153:214-42.
Ross PD, Subramanian S. Thermodynamics of macromolecular association reactions: analysis of forces contributing to stabilization. Biophys J. 1980;32(1): 79-81. https://doi.org/10.1016/S0006-3495(80)84918-6.

Ross PD, Subramanian $\mathrm{S}$. Thermodynamics of protein association reactions: forces contributing to stability. Biochemistry. 1981;20(11):3096-102. https://doi.org/1 0.1021/bi00514a017.

Seedher N, Bhatia S. Reversible binding of celecoxib and valdecoxib with human serum albumin using fluorescence spectroscopic technique. Pharmacol Res. 2006;54(2):77-84. https://doi.org/10.1016/j.phrs.2006.02.008.

Seeliger D, De Groot BL. Ligand docking and binding site analysis with PyMOL and AutodockNVina. J Comput Aided Mol Des. 2010;24(5):417-22. https://doi. org/10.1007/s10822-010-9352-6.

Shen X, Zhou N, Mi L, Hu Z, Wang L, Liu X, et al. Phloretin exerts hypoglycemic effect in streptozotocin-induced diabetic rats and improves insulin resistance in vitro. Drug Des Devel Ther. 2017;11:313-24. https://doi.org/10.2147/DDDT. S127010.

Shi JH, Liu TT, Jiang M, Chen J, Wang Q. Characterization of interaction of calf thymus DNA with gefitinib: spectroscopic methods and molecular docking. J Photochem Photobiol B Biol. 2015;147:47-55. https://doi.org/10.1016/j. jphotobiol.2015.03.005.

Shi JH, Zhu YY, Wang J, Chen J, Shen YJ. Intermolecular interaction of prednisolone with bovine serum albumin: spectroscopic and molecular docking methods. Spectrochim Acta A Mol Biomol Spectrosc. 2013;103:28794. https://doi.org/10.1016/j.saa.2012.11.034.

Shu G, Lu NS, Zhu XT, Xu Y, Du MQ, Xie QP, et al. 2014. Phloretin promotes adipocyte differentiation in vitro and improves glucose homeostasis in vivo. J Nutr Biochem. 2014;25(12):1296-308.

Sigma-Aldrich Co.. Product information insulin from bovine pancreas. 2014: p.2-3. http://www.sigmaaldrich.com/.

Soleymani H, Saboury AA, Moosavi-Movahedi AA, Rahmani F, Maleki J, Yousefinejad S, et al. Vitamin E induces regular structure and stability of human insulin, more intense than vitamin D3. Int J Biol Macromol. 2016;93(Pt A):868-78. https://doi.org/10.1016/j.ijbiomac.2016.09.047.

Suhartati T. Dasar-Dasar Spektrofotometri Uv-Vis Dan Spektrometri Massa Untuk Penentuan Struktur Senyawa Organik. Bandar Lampung: CV. Anugrah Utama Raharja; 2017. www.aura-publishing.com

Tang J, Luan F, Chen X. Binding analysis of glycyrrhetinic acid to human serum albumin: fluorescence spectroscopy, FTIR, and molecular modeling. Bioorg Med Chem. 2006;14(9):3210-7. https://doi.org/10.1016/j.bmc.2005.12.034.

Verdian-Doghaei A, Housaindokht MR. Spectroscopic study of the interaction of insulin and its aptamer - sensitive optical detection of insulin. J Lumin. 2015; 159:1-8. https://doi.org/10.1016/j.jlumin.2014.10.025.

Wang S, Xu X, Liu Q, Xie Y. The application of fluorescence spectroscopy in the study on protein conformation. Prog Chem. 2001;13(4):257-60.

Wang Y, Guo R, Xi J. Comparative studies of interactions of hemoglobin with single-chain and with gemini surfactants. J Colloid Interface Sci. 2009;331(2): 470-5. https://doi.org/10.1016/j.jcis.2008.12.020.

Wani TA, Alsaif N, Alanazi MM, Bakheit AH, Zargar S, Bhat MA. A potential anticancer dihydropyrimidine derivative and its protein binding mechanism by multispectroscopic, molecular docking and molecular dynamic simulation along with its in-silico toxicity and metabolic profile. Eur J Pharm Sci. 2021a; 158:105686. https://doi.org/10.1016/j.ejps.2020.105686.

Wani TA, Alsaif N, Bakheit AH, Zargar S, Al-Mehizia AA, Khan AA. Interaction of an abiraterone with calf thymus DNA: investigation with spectroscopic technique and modelling studies. Bioorg Chem. 2020a;100(May):103957. https://doi.org/10.1016/j.bioorg.2020.103957.

Wani TA, Bakheit AH, Zargar S, Alanazi ZS, Al-Majed AA. Influence of antioxidant flavonoids quercetin and rutin on the in-vitro binding of neratinib to human serum albumin. Spectrochim Acta A Mol Biomol Spectrosc. 2021b;246: 118977. https://doi.org/10.1016/j.saa.2020.118977.

Wani TA, Bakheit AH, Zargar S, Rizwana H, Al-Majed AA. Evaluation of competitive binding interaction of neratinib and tamoxifen to serum albumin in multidrug therapy. Spectrochim Acta A Mol Biomol Spectrosc. 2020b;227: 117691. https://doi.org/10.1016/.saa.2019.117691.

Werdinius B. Effect of temperature on the action of reserpine. Acta Pharmacol Toxicol. 1962;19(1):43-6.

Whittingham JL, Scott DJ, Chance K, Wilson A, Finch J, Brange J, et al. Insulin at pH 2: Structural analysis of the conditions promoting insulin fibre formation. J Mol Biol. 2002;318(2):479-90. https://doi.org/10.1016/ S0022-2836(02)00021-9. 
Yang H, Xiao X, Zhao X, Wu Y. Intrinsic fluorescence spectra of tryptophan, tyrosine and phenyloalanine. In: 5th International Conference on Advanced Design and Manufacturing Engineering (ICADME); 2015. p. 224-33.

Yao SZ, Chen P, Yang XY, Fung YS, Si SH. Herbal organic acids. J Chromatogr Libr. 1998;60(C):343-70. https://www.sciencedirect.com/science/article/abs/pii/S03 01477008603061. https://doi.org/10.1016/S0301-4770(08)60306-1.

Zargar S, Alamery S, Bakheit AH, Wani TA. Poziotinib and bovine serum albumin binding characterization and influence of quercetin, rutin, naringenin and sinapic acid on their binding interaction. Spectrochim Acta A Mol Biomol Spectrosc. 2020;235:1 18335. https://doi.org/10.1016/j.saa.2020.118335.

Zhang G, Que Q, Pan J, Guo J. Study of the interaction between icariin and human serum albumin by fluorescence spectroscopy. J Mol Struct. 2008; 881(1-3):132-8. https://doi.org/10.1016/..molstruc.2007.09.002.

Zhang G, Zhao N, Hu X, Tian J. Interaction of alpinetin with bovine serum albumin: probing of the mechanism and binding site by spectroscopic methods. Spectrochim Acta A Mol Biomol Spectrosc. 2010;76(3-4):410-7. https://doi.org/10.1016/.jsaa.2010.04.009.

\section{Publisher's Note}

Springer Nature remains neutral with regard to jurisdictional claims in published maps and institutional affiliations.

\section{Submit your manuscript to a SpringerOpen ${ }^{\circ}$ journal and benefit from:}

- Convenient online submission

- Rigorous peer review

- Open access: articles freely available online

- High visibility within the field

- Retaining the copyright to your article

Submit your next manuscript at $\boldsymbol{\nabla}$ springeropen.com 